\title{
Cervical Spinal Cord Injury Complicating Ankylosing Spondylitis
}

\author{
Dominic Foo, M.D. ${ }^{1.2,3}$, Mehdi Sarkarati, M.D. ${ }^{1,4}$ and Victoria \\ Marcelino, M.D. ${ }^{5}$ \\ ${ }^{1}$ Spinal Cord Injury, ${ }^{2}$ Neurology Services, West Roxbury Veterans Administration \\ Medical Center and Departments of ${ }^{3}$ Neurology and ${ }^{4}$ Neurosurgery, Harvard \\ Medical School, Boston, Massachusetts, ${ }^{5}$ Spinal Cord Injury Service, Veterans \\ Administration Medical Center, Richmond, Virginia, U.S.A.
}

\section{Summary}

Within a period of 12 years 466 patients with acute spinal cord injury were admitted to our Centre, seven of these having ankylosing spondylitis ( $A S)$. A history of alcohol consumption preceding the accident was present in five patients, and in four there was a history of neurological deterioration before their admission. An epidural hematoma was found in one patient and four expired within 3 months of their injury.

The incidence of ankylosing spondylitis in cervical cord injury was $1.5^{\circ}$, and an associated epidural hematoma was present in some $14 \%$ of the patients. The mortality rate was $57 \%$. There was a high incidence of alcoholic use before the accident. Neurological deterioration commonly occurred before admission.

Key words: Ankylosing spondylitis; Cervical cord injury; Cervical fracture.

\section{Introduction}

The spine in ankylosing spondylitis (AS) is prone to minor injury (Føo et al., 1983) because of the loss of the normal flexibility, mobility, and elasticity of the rigid vertebral column. However, spinal fractures associated with AS are uncommon (Kewalramani et al., 1975; Wilkinson and Bywaters, 1958). When a complete fracture does occur it is very unstable and is associated with a high risk of neurological deterioration (Hunter and Dubo, 1978; Kewalramani et al., 1975). The survival of spinal cord injured patients in general has greatly improved since World War II but the mortality rate in AS patients with a cervical fracture has remained high (Kewalramani et al., 1975; Hollin et al., 1965; Woodruff and Dewing, 1963). Although post-traumatic spinal epidural bleeding can be associated with cervical spondylosis or ankylosing spinal hyperostosis (Foo and Rossier, 1982), it is more commonly seen in patients with AS (Bohlman, 1979; Farhat et al., 1973). Apart from the experience of Guttmann (1966), there has

Requests for reports: Dominic Foo, M.D., Veterans Administration Medical Center, 1400 VFW

Parkway, West Roxbury, MA 02132, U.S.A.

This paper was presented at the Annual Meeting of the American Spinal Injury Association, April 15-17, 1985, Atlanta, Georgia, U.S.A.

This paper was supported in part by the New England Paralyzed Veterans of America. 
been no other reported incidence of traumatic myelopathy complicating AS in a Spinal Cord Injury Centre. The purpose of this paper is to assess the incidence of cervical cord injury in AS patients in our Centre, to assess the associated incidence of epidural bleeding, to re-evaluate the mortality rate in these patients, and to identify other factors that may predispose such patients to injury.

\section{Materials and Methods}

From May 1, 1973 to May 31, 1985, 466 patients with acute spinal cord injury were admitted to our Spinal Cord Injury Centre, excluding those with spinal fractures without myelopathy or non-traumatic spinal cord lesions; the majority of these patients were admitted within 6 weeks of their injury. Cervical cord injury, associated with AS (which was demonstrated by spinal and sacroiliac joint radiography), was present in seven patients who had been followed by us at least once per year since their injury. During this period of time there was no AS patient with dorsal or lumbar spinal cord trauma. Excluding four patients who expired within 3 months of the injury, the follow-up period of the other three subjects ranged from 5 to 7 years (mean, 5.4 years) after their injury. The medical records of these seven patients were reviewed at length with regard to their clinical history, physical examination, clinical course, management, and complications. AS patients with traumatic cervical fractures or radiculopathy without myelopathy were excluded from our study.

\section{Results}

Because of the predominant veterans population of our Centre the great majority of the patients were male. The ages of the AS patients studied, six males and one female, were from 60 to 81 years (mean, 67 years) at the time of their injury. Five patients were admitted within 3 days of their trauma and the other two subjects were seen by us 7 and 11 weeks after their injury, respectively. The causes of the trauma were as follows: three patients fell whilst walking; one fell off his bed; one fell down a flight of stairs; one fell from a height of 20 feet and one was involved in an automobile accident. A history of alcoholic use preceding the accident was obtained in five patients, either from the patient himself or from his family; however, blood alcohol levels were not obtained in these patients. Spinal fracture or dislocation was observed at the C3-4 segment in one patient, C5-6 segment in one, and C6-7 segment in three. One patient had no spinal fracture; in another patient, who was very obese and had a very short neck, the nature of the spinal injury was not known because the lower cervical vertebrae could not be shown adequately radiographically. The mechanism of the injury was extension in six patients and flexion in one, as determined by the nature of the accident, the presence of associated injuries, and the radiological findings. The posttraumatic myelopathy at admission was sensory and motor complete in five patients, sensory complete but motor densely incomplete in one, and sensory and motor incomplete in the remaining case. In four patients there was a history of neurological deterioration before admission; three patients were initially able to get up and walk before their spinal cord lesions became complete. Three patients 
Table 1 Mortality rate in patients with ankylosing spondylitis with a cervical fracture

\begin{tabular}{lc}
\hline Author and year & $\begin{array}{c}\text { Mortality rate } \\
\text { Hollin et al., 1965 }\end{array}$ \\
Kewalramani et al., 1975 & 45 \\
Murray and Persellin, 1981 & 40 \\
Woodruff and Dewing, 1963 & 45 \\
\hline
\end{tabular}

Table 2 Mortality rate in patients with ankylosing spondylitis with a cervical cord injury

\begin{tabular}{lc}
\hline Author and year & \begin{tabular}{c} 
Mortality rate \\
\hline Foo et al., 1985
\end{tabular} \\
Hunter and Dubo, 1983 & 57 \\
Young et al., 1977-78 & 30 \\
\hline
\end{tabular}

were initially treated with a collar: one patient had no fracture; another had a stable fracture through the C6-7 disc with a complete myelopathy; in the third patient the type of vertebral injury was not known. The other four patients with fracture-dislocation had skull traction. Marked neurological recovery was seen in one who had no spinal fracture and a grossly incomplete spinal cord lesion. One patient had only slight return of motor function and four had no improvement. Another two patients developed further neurological loss when on skeletal traction. Operative reduction and fixation of the fractured spine was performed in two patients with no post-operative improvement; a moderate-size hematoma (10-15 $\mathrm{ml}$ ) was found at the operation in one patient. Three patients died from cardiac asystole, pneumonia, and status epilepticus, respectively; and another expired as the result of an ascending cervical myelopathy within 3 months of the injury. Necropsy was carried out in two patients; neither showed evidence of spinal epidural bleeding.

The literature was reviewed with regard to the mortality rate of AS patients who had cervical fractures (Table 1) or myelopathy (Table 2), excluding patients with dorsal or lumbar spine or spinal cord injury.

\section{Discussion}

There have been many publications in the literature on the occurrence of spinal or spinal cord injury in AS patients (Guttmann, 1966; Hollin et al., 1965; Hunter and Dubo, 1983; Kewalramani et al., 1975; Murray and Persellin, 1981; Weinstein et al., 1982; Wilkinson and Bywaters, 1958; Woodruff and Dewing, 1963). However, few authors described its incidence in these patients. In a review of 2,500 patients with spinal injury Guttmann (1966) found only seven with AS and 
five of his seven patients had traumatic tetraplegia. Wilkinson and Bywaters (1958) noted two patients with lumbar fracture in a review of 222 AS patients who were followed for from one to 20 years (mean, 4.6 years). Weinstein et al. (1982), in their study of 105 consecutive cases of AS, noticed that the frequency of spinal fracture was 12 per cent and the frequency of myelopathy was 8 per cent. In our study, the incidence of cervical cord injury in AS patients was 1.5 per cent over a period of 12 years. If we had also included AS patients with traumatic cervical fracture or radiculopathy without myelopathy and patients with dorsal or lumbar spinal or spinal cord trauma, the incidence of spinal injury would have been higher.

A minor fall is a common cause of spinal cord injury in AS patients (Hollin et al., 1965; Hunter and Dubo, 1983; Murray and Persellin, 1981; Young et al., 1977-78) and four of our seven patients sustained a cervical cord lesion after a minor fall. Because of this Young et al. (1977-78) suggested that these patients should observe certain preventative measures such as having night-lights in the bedroom, bathroom, and dimly lit halls, and using handrails when they are going up or down stairs. Weinstein et al. (1982) noted that some of their AS patients fell because they could not see the ground ahead while walking, due to progressive dorsal kyphosis, and they proposed that such patients should be counselled to exercise caution during ambulation. Grisolia et al. (1967), Murray and Persellin (1981), Rand and Stern (1961), and Woodruff and Dewing (1963) all reported a history of alcoholic intoxication in some of their AS patients who sustained a spinal cord lesion after a fall. In five of our patients there was also a history of alcoholic use which was probably a contributory factor in their injury. It is suggested that AS patients should not drink excessively as this may interfere with their ability to walk safely. Our study showed a high incidence of major neurological deterioration after a fall $\left(4 / 7\right.$ or $57.1^{\bullet}$ ) , indicating that these patients should also be educated in the potentially grave consequences of even a minor injury.

Post-traumatic spinal epidural bleeding is rare, accounting for 1 to 2 per cent of traumatic cord injury (Foo and Rossier, 1982). It is typically seen in the young patient without vertebral damage or in the older individual who has arthritic changes of the spine (Foo and Rossier, 1982), especially in the patient with AS (Bohlman, 1979; Farhat et al., 1973; Grisolia et al., 1967). In their review of the literature Hunter and Dubo (1983) noted that there was evidence of spinal epidural bleeding in nine out of $54\left(16.7^{\circ}\right.$ ) AS patients who had spinal fractures. An epidural hematoma was noted in one of our four patients who had an operation or autopsy; in the other three patients, there was no clinical evidence of neurological progression to suggest cord compression by a hematoma. Evidently, the incidence of an associated spinal epidural hematoma is higher in AS patients than in other subjects with spinal cord injury as the bleeding frequently arises from the oozing, waxy surface of the fractured cancellous bone affected by AS (Farhat et al., 1973).

In a review of 105 AS patients by Weinstein et al. (1982), 13 had a spinal fracture, which was associated with a mortality rate of 29 per cent. However, in these 13 patients, only five had a cervical injury and eight had severe cord trauma. The reported early mortality rate of AS patients with cervical fracture in the literature ranged from 35 to 45 per cent (Table 1), which was considerably higher 
than that seen with fractures involving normal spines (Janda et al., 1968; Murray and Persellin, 1981). However, some of the patients reviewed by Hollin et al. (1965), Kewalramani et al. (1975), Murray and Persellin (1981), and Woodruff and Dewing (1963) had no myelopathy. Our study is in agreement with Young et al. (1977-78) in that these patients have a grim prognosis for potential fatality (Table 2), especially if they are old and have a complete cord lesion. In the patients of Hunter and Dubo (1983), after excluding those without cervical myelopathy, the mortality rate was 30 per cent $(3 / 10)$, which was lower than that of our patients $\left(57^{\circ}\right)$. The mean age of their patients was 62.3 years (range, 45 to 76 ), whereas the average age of our subjects was 66.6 years (range, 60 to 81 years); 50 per cent $(5 / 10)$ of their patients had complete myelopathy while 71.4 per cent $(5 / 7)$ of our subjects had complete cervical lesions. Only one of our three patients who were treated with a collar expired, whereas three of the four subjects who were initially treated with skull traction died within 3 months of their trauma. This is because all the patients in the latter group had complete cord lesions which were associated with severe medical complications. Immobilization with a collar is undoubtedly not the preferred mode of treatment but it may be indicated in selected patients.

\section{Résumé}

D'un groupe de 466 patients avec traumatisme aigu de la moelle épinière admis dans notre centre durant une période de 12 ans, 7 étaient atteints de spondylite ankylosante. Cinq patients se présenterent avec une histoire de consommation d'alcool avant l'accident et chez 4 patients l'état neurologique s'était détérioré avant leur admission. Un hématome épidural fut découvert chez un patient et 4 patients expirèrent dans les 3 mois suivant leur trauma.

Un trauma de la moelle cervicale complique la spondylite ankylosante dans $1.5^{\circ}{ }^{\circ}$, des cas et chez environ $14^{\circ}{ }_{0}$, des patients un hématome épidural est présent. Le taux de mortalité est de $57^{\circ}{ }_{0}$. La consommation d'alcool avant l'accident et la détérioration de l'état neurologique avant l'hospitalisation sont fréquentes.

\section{Zusammenfassung}

Innerhalb eines Zeitabschnittes von 12 Jahren wurden 466 Patienten mit akuter Rueckenmarksverletzung in unser Zentrum eingewiesen und 7 hatten spondylitis ankylopoetica. Alkohol Konsum vor dem Unfall wurde bei 5 Patienten festgestellt und bei 4 Patienten ging eine neurologische Verschlechterung der Einweisung voraus. Ein epidurales Haematom wurde in einem Patienten festgestellt und 4 Patienten starben innerhalb von 3 Monaten nach ihrer Verletzung.

Die Haeufigkeit von spondylitis ankylopoetica bei zervikalen Rueckenmarksverletzungen ist $1.5^{\circ}$ ") und bei $14^{\circ}{ }^{\circ}$ der Patienten ist ein epidurales Haematom gegenwaertig. Die sterblichkeitsrate ist $57^{\circ}{ }^{\circ}$. Alkohol Konsum vor dem Unfall ist haeufig, ebenso eine neurologische Verschlechterung vor der Einweisung.

\section{References}

Bohlman HH, 1979 Acute fractures and dislocations of the cervical spine: An analysis of three hundred hospitalized patients and review of the literature. Journal of Bone \& Joint Surgery 61A:1119-1142.

FARHAT SM, SCHNEIDER RC, GRAY JM 1973 Traumatic spinal extradural hematoma associated with cervical fractures in rheumatoid spondylitis. Journal of Trauma 13:591-599.

Foo D, Bignami, A Rossier AB 1982 Post-traumatic spinal epidural hematoma. Neurosurgery $11: 25-32$.

Foo D, Rossier AB 1983 Two spinal cord lesions in a patient with ankylosing spondylitis and cervical spine injury. Neurology (Ny) 33:245-249.

Grisolia A, Bell RL, Peltier LF 1967 Fractures and dislocations of the spine complicating 
ankylosing spondylitis. A report of six cases. Journal of Bone \& Joint Surgery 49A:339-345.

Guttmann L 1966 Traumatic paraplegia and tetraplegia in ankylosing spondylitis. Paraplegia 4:188-203.

Hollin SA, Gross SW, LEvin P 1965 Fracture of the cervical spine in patients with rheumatoid spondylitis. American Surgeon 31:532-536.

Hunter T, Dubo H 1978 Spinal fractures complicating ankylosing spondylitis. Clinical review. Annals of Internal Medicine 88:546-549.

Hunter T, Dubo HIC 1983 Spinal fractures complicating ankylosing spondylitis. A long-term followup study. Arthritis and Rheumatism 26:751-759.

Janda WE, Kelly PJ, Rhoton AL, LAyton DD 1968 Fracture-dislocation of the cervical part of the spinal column in patients with ankylosing spondylitis. Mayo Clinic Proceedings 43:714-721.

KeWALRAMANi LS, TAYLOR RG, AlBRAND OW 1975 Cervical spine injury in patients with ankylosing spondylitis. Journal of Trauma 15:931-934.

Murray GC, Persellin RH 1981 Cervical fracture complicating ankylosing spondylitis. A report of eight cases and review of the literature. American Journal of Medicine 70:1033-1041.

RAND RW, STERN WE 1961 Cervical fractures of the ankylosed rheumatoid spine. Neurochirugia 4:137-148.

Weinstein PR, Karpman RR, Gall EP, Pitt M 1982 Spinal cord injury, spinal fracture, and spinal stenosis in ankylosing spondylitis. Journal of Neurosurgery 57:609-616.

Wilkinson M, Bywaters EGL 1958 Clinical features and course of ankylosing spondylitis. As seen in a follow-up of 222 hospital referred cases. Annals of Rheumatic Diseases 17:209-228.

WoODRUFF FP, DEwING SB 1963 Fracture of the cervical spine in patients with ankylosing spondylitis. Radiology 80:17-21.

Young JS, Cheshire DJE, Pierce JA, Vivian JM 1977-78 Cervical ankylosis with acute spinal cord injury. Paraplegia 15:133-146. 